\title{
APLICAÇÃO, EM PRÉ-COLHEITA, DE DESSECANTE EM DUAS \\ CULTIVARES DE SOJA (Glycine max (L.) Mer ril) III - EFEITOS SOBRE A COMPOSIÇÃO QUÍMICA (PROTEÍNA, ÓlEO E CINZAS) E RESÍdUOS NAS SEMENTES.
}

\section{RESUMO}

A aplicação pré-colheita do dessecante paraquat, quando realizada a partir das primeiras épocas (75 e 72 dias após o início do florescimento, para a Santa Rosa e IAC-2, respectivamente) não modificaram os teores com que ocorreram normalmente, proteína, extrato etéreo e cinzas nos grãos.

As análises do resíduo de paraquat nos grãos colhidos, mostram claramente que não se deve recomendar tal prática às lavouras de soja, cujo objetivo final seja o fornecimento de grãos para a alimentação humana e animal. Entretanto pode ser indicada, sem maiores restrições, àquelas cuja finalidade é a produção de sementes comerciais.

PALAVRAS CHAVE: dessecante, semente, composição química, resíduo.

\section{SUMMARY}

This work showed that the application of paraquat to either determinate or indeterminate cultivars of soybean when the seeds have reached physiological maturity does not affect the chemical composition but it was verified that the levels of paraquat residue in the grains was too high for

\author{
J.C.DURIGAN* J.F. DURIGAN** \\ N.M. CARVALHO $* * *$ \\ * Prof. da Disciplina de "Herbicidas e Plantas \\ Daninhas" da Faculdade de Ciências Agrárias e \\ Veterinárias de Jaboticabal - UNESP. \\ ** Prof. da Disciplina de "Tecnologia dos Produ tos \\ Agropecuários" da FCAV de Jaboticabal - UNESP. \\ *** Prof. da Disciplina de "Tecnologia de Semen - \\ tes" da FCAV de Jaboticabal - UNESP \\ Parte da dissertação do primeiro autor para \\ obtenção do grau de Mestre em Ciências, pela \\ UNESP.
}

the material to be recommended for human or animal consumption.

KEY WORDS: desiccant, seed, chemical composition, residue.

\section{INTRODUÇÃO}

Em algumas regiões onde a colheita muitas vezes coincide com condições de altas temperaturas e intensas precipitações pluviométricas, o retardamen to na retirada das sementes de soja do campo pode levar a sérias perdas tanto na sua qualidade como na sua quantidade.

A aplicação de um produto dessecante por época da maturidade fisiológica das sementes, pode ser a solução para este problema, desde que tal prática não traga nenhuma mudança prejudicial a importantes constituintes dos grãos (óleo, proteína e cinzas) e nem deixe resíduos químicos do produto nas sementes. 
Os produtos e as doses de dessecantes usados, normalmente não afetam os teores de proteína e óleo nos grãos de soja, segundo Tabin \& Skalki (24). Recentemente, mostrou-se que o paraquat não traz problemas aos teores de óleo, proteína e cinzas dos grãos de soja, quando aplicado depois de 54 dias após o florescimento (12); no entanto, afirmam os autores que a aplicação não deve ser feita antes dos 75 dias, pois acarretaria problemas à quantidade total acumulada dos elementos citados anteriormente.

A análise de resíduo do dessecante químico aplicado deve ser realizada, principalmente quando o produto final colhido se destina à alimentação, ou quando se tratam de moléculas com capacidade de translocação nas plantas tratadas (9).

Análises feitas em sementes de beterraba mostraram que as parcelas colhidas sete dias após a aplicação apresentaram 2 a 4 ppm de resíduo do ion diquat. Quando colhidas 14 dias após estes valores já tinham caído pela metade (2).

Os testes também já mostraram que dois dias após o tratamento com diquat $(4,2 \mathrm{~kg} / \mathrm{ha})$ em pastagens (18), havia grande quantidade de residuo do produto (200 $\mu \mathrm{g} / \mathrm{g}$ semente), que foi diminuindo com o passar dos dias. Outros autores, no entanto, já encontraram ausência total de resíduos quími-cos nas sementes de soja (4).

No presente trabalho, após a aplicação do paraquat em diferentes épocas antes da colheita das sementes de soja, foram feitas análises para se verificar a possibilidade de ocorrência ou não de alterações na composição química (proteína, óleo e cinzas) e resíduo do produto, nas sementes.

\section{MATERIAIS E MÉTODOS}

Os tratamentos constaram de aplicações do produto dessecante, semanalmente, a partir dos primeiros 72 e 75 dias após iniciado o floresci- mento, para as cultivares IAC-2 e Santa Rosa, respectivamente. Tais épocas foram estabelecidas em função dos teores de umidade dos grãos, que estavam ao redor de $56,8 \%$ para a Santa Rosa e $57,5 \%$ para IAC-2. Cada tratamento semanal teve sua respectiva comparação (não tratado) e além disso houve a testemunha geral, ou seja, aquele tratamento no qual as plantas foram colhidas obedecendo-se o critério usual dos agricultores.

O produto usado foi o paraquat* $11,1^{\prime}$ dimetil-4,4' bipiridilium-ion) $20 \%$, na dose de 2,0 litros do produto comercial por hectare.

Do total de grãos colhidos em cada parcela, tomou-se uma amostra representativa que fbi enviada para aná lises no laboratório de Tecnologia dos Produtos Agropecuários da Faculdade de Ciências Agrárias e Veterinárias de Jaboticabal.

Cada uma dessas amostras foi moída em moinho de laboratório, até a finura de 80 mesh, e com o material assim preparado, foram determinados os teores de proteína, extrato etéreo e cinzas.

O teor protéico (\%) foi calculado através da multiplicação do teor (\%) de nitrogénio total pelo fator 6,25 (1). O teor de nitrogênio total foi determinado pelo método microkiveldahl e para tal baseou-se nos métodos propostos pela AOAC (1) e Sarruge \& Haag (20).

Para a determinação do extrato etéreo, utili zou-se a extração direta com éter de petróleo num extrator Soxhlet, conforme metodologia proposta pela AOAC (1). 0 teor (\%) de cinzas também foi determinado conforme metodologia proposta por essa mesm ${ }^{a}$ associação.

Para as análises de resíduo, o material foi enviado para o laboratório pertencente à Cia. Imperial de Indústrias Químicas (ICI), sediado na Jeallot's Hill Research Station, cidade de Bracknell, Inglaterra.

As análises foram realizadas cinco meses após a colheita, considerando-se este tempo como um período de armazenamento normal de grãos ou sementes comerciais.

O aparelho utilizado para estas análises apresentava uma sensibilidade para detecção de até $0,05 \mathrm{ppm}$ do paraquat. A taxa de recuperação obtida para o método empregado, foi de $51 \%$ para um padrão de $0,5 \mathrm{ppm}$ e de 54 a $61 \%$ para o de 1,0 ppm.

\section{RESULTADOS E DISCUSSÃO}

Os dados sobre os conteúdos proteico, lipídico e de cinzas, expressos em gramas por 100 gramas de matéria seca, para as duas cultivares, encontram-se no quadro 1.

\footnotetext{
- produto comercial = GRAMOXONE
} 
QUADRO 1. Conteúdos protéico, lipidico, e de cinzas, expressos em gramas por 100 gramas de matéria seca de sementes de soja obtidas de plantas artificialmente dessecadas ou não com paraquat, em diferentes épocas após o início do florescimento, para as cultivares Santa Rosa e IAC-2.

\begin{tabular}{|c|c|c|c|c|c|c|c|c|}
\hline \multirow{2}{*}{\multicolumn{2}{|c|}{$\begin{array}{c}\text { Tratamentos } \\
\text { (dias após o florescimento }\end{array}$}} & & \multicolumn{6}{|c|}{ Frạ̧ōes ( $\mathrm{g} / 100 \mathrm{~g}$ de matéria seca) } \\
\hline & & & \multicolumn{2}{|c|}{ proteína } & \multicolumn{2}{|c|}{ extrato etéreo } & \multicolumn{2}{|c|}{ cinzas } \\
\hline Sta. Rosa & IAC-2 & & Sta. Rosa & IAC-2 & Sta. Rosa & IAC-2 & Sta. Rosa & IAC-2 \\
\hline 75 & 72 & $\begin{array}{l}\text { T } \\
\text { NT }\end{array}$ & $\begin{array}{l}38,7 \\
39,8\end{array}$ & $\begin{array}{l}37,1 \\
36,6\end{array}$ & $\begin{array}{l}20,9 \\
21,5\end{array}$ & $\begin{array}{c}22,1 \\
22,2\end{array}$ & $\begin{array}{l}4,9 \\
5,2\end{array}$ & $\begin{array}{l}5,4 \\
4,7\end{array}$ \\
\hline 82 & 79 & $\begin{array}{l}\mathrm{T} \\
\mathrm{NT}\end{array}$ & $\begin{array}{l}37,4 \\
38,7\end{array}$ & $\begin{array}{l}36,9 \\
38,9\end{array}$ & $\begin{array}{l}21,3 \\
20,1\end{array}$ & $\begin{array}{l}21,4 \\
20,3\end{array}$ & $\begin{array}{l}4,8 \\
5,0\end{array}$ & $\begin{array}{l}5,3 \\
5,1\end{array}$ \\
\hline 89 & 86 & $\begin{array}{l}\text { T } \\
\text { NT }\end{array}$ & $\begin{array}{l}37,7 \\
37,5\end{array}$ & $\begin{array}{l}36,6 \\
26,9\end{array}$ & $\begin{array}{l}21,3 \\
20,9\end{array}$ & $\begin{array}{l}21,2 \\
22,6\end{array}$ & $\begin{array}{l}4,9 \\
5,0\end{array}$ & $\begin{array}{l}5,2 \\
5,2\end{array}$ \\
\hline 96 & 93 & $\begin{array}{l}T \\
\text { NT }\end{array}$ & $\begin{array}{l}38,9 \\
38,2\end{array}$ & $\begin{array}{l}37,1 \\
36,3\end{array}$ & $\begin{array}{l}21,4 \\
19,6\end{array}$ & $\begin{array}{l}21,5 \\
21,0\end{array}$ & $\begin{array}{l}5,0 \\
5,1\end{array}$ & $\begin{array}{l}4,9 \\
5,2\end{array}$ \\
\hline 103 (Test) & 100 & & 38,7 & 37,8 & 20,3 & 21,4 & 5,0 & 4,6 \\
\hline $\begin{array}{l}\text { F } \\
\text { C.V. (\%) }\end{array}$ & & & $\begin{array}{l}0,80^{\text {ns }} \\
4,56\end{array}$ & $\begin{array}{l}0,88^{n s} \\
4,52\end{array}$ & $\begin{array}{l}1,61^{\text {ns }} \\
5,21\end{array}$ & $\begin{array}{l}1,11^{\mathrm{ns}} \\
6,30\end{array}$ & $\begin{array}{l}0,30^{\text {ns }} \\
9,01\end{array}$ & $\begin{array}{l}0,90^{\text {ns }} \\
10,89\end{array}$ \\
\hline
\end{tabular}

QUADRO 2. Resíduo do paraquat (mg/kg) em grãos de soja das cultivares Santa Rosa e IAC-2, colhidas uma semana após as aplicações. Análise de residuos realizada em 10.09.1978.

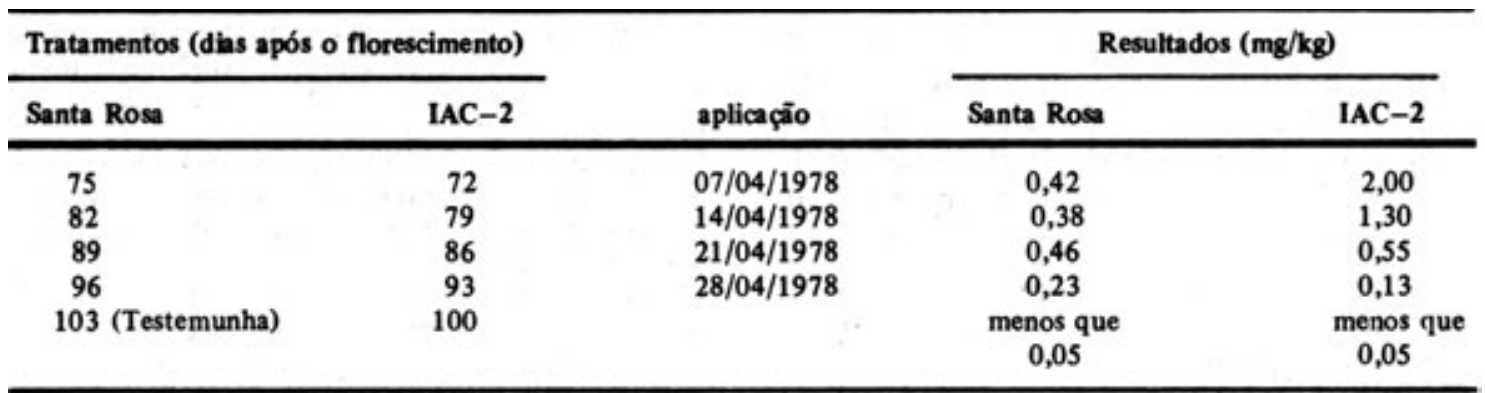

Os teores dos constituintes analisados nos grãos não diferiram significativamente em nenhuma das épocas, tanto nas parcelas tratadas como nas não tratadas, para as duas cultivares.

Esses resultados concordam com os obtidos por Rubel et al. (19), que encontraram valores constantes e iguais aos obtidos no final, para os teores de proteína, óleo e ácidos graxos, aos 65 dias após o florecimento, em três cultivares comerciais de soja (Acne, Chippewa e Harosoy) (63).
Trabalho realizado por Durigan et al. (12) mostrou claramente que aplicações feitas muito precocemente (antes da maturidade fisiológica) podem acarretar reduções drásticas na quantidade de produto colhido, sem afetar sua qualidade ou seja, o dessecante paraquat, quando foi aplicado 54 dias após o início do florescimento (na cultivar "Viçoja"), não modificou os teores com que normalmente ocorrem esses constituintes nos grãos. Entretanto, o tratamento não foi indicado para antes dos 75 dias 
após o início do florescimento, pois isto provocou uma redução na quantidade total acumulada destes componentes.

O não interrelacionamento entre os processos de acúmulo lipídico e protéico foi mostrado por Garner et al. (15), que afirmaram ser estes constituintes acumulados simultaneamente em determinada época do ciclo, porém, não encontraram evidência da existência de uma relação direta entre tais mecanismos

Sabe-se ainda, de acordo com trabalho de Ivanov citado por Garner et al. (15), que existe um período de intensa formação de óleo durante o ciclo, o qual corresponderia à metade entre o florescimento e a maturação final das sementes. Para o trabalho em questão, estas épocas estariam em torno de 51 e 52 dias após o início do florescimento, respectivamente para as cul tivares Santa Rosa e IAC-2.

As duas cultivares testadas apre sentaram teores dos constituintes ana lisados, dentro do padrão esperado para cada uma e de valores pare cidos entre ambas.

As aplicações feitas na primeira época, embora bem precoce, provavelmente ocorreram após a semente já ter atingido os seus teores finais dos componentes analisados no presente en saio.

Pode-se concluir, em vista dos dados, que a técnica do dessecamento pré-colheita, desde que realizada no mínimo 75 e 72 dias após o início do florescimento (respectivamente para a cultivar Santa Rosa e IAC-2), não afetará os conteúdos protéico, lipídico e de cinzas das sementes.

Pode-se observar pelo quadro 2, que as quantidades de residuo do paraquat, mostram-se bastante superiores ao limite máximo de resíduo estabelecido pela WHO/FAO (26) em relação a este produto, na cultura da soja. Para os grãos, na forma em que se encontram ao término da colheita, o limite máximo estabelecido pelas organizações anteriores citadas é de $0,1 \mathrm{mg} / \mathrm{kg}$.
Para todas as épocas de aplicação, nas duas cultivares estudadas, a quantidade residual detectada foi sempre maior do que o limite permitido, chegando a 20 vezes mais como ocorreu para a primeira época de aplicação na cultivar IAC- 2 .

Os resultados obtidos no mundo, por diversos autores, mostram-se bastante contraditórios, de tal forma que esse tipo de avaliação se reveste, a cada dia que passa, de crescente importância, visando-se a obtenção de produtos agricolas totalmente isentos de resíduos tóxicos de qualquer natureza.

Gigax \& Burnside (16), com aplicações de $1,12 \mathrm{~kg} /$ ha do paraquat em sorgo, detectaram resíduos nos grãos que variaram entre 0,08 e 0,36 ppm. De acordo com Hilton (17) estes níveis de resíduos estão muito abaixo da quantidade necessária para causar toxicidade crônica em cães, que é de 85 ppm na ração diária.

Vários outros trabalhos já tentaram esclarecer a respeito do modo de ação e degradação do paraquat e do diquat em diversas culturas $(3,5,6,7,8,10,11,13$, $14,21,22,23,25,27$ ).

Com base nos resultados obtidos, nota-se claramente que não se deve proceder à recomendação de tal prática em lavouras de soja, cujo objetivo final do produto colhido seja a alimentação humana e/ou animal; pelo menos até o surgimento de provas para uma elucidação final e conclusiva do problema. Entretanto, o dessecamento précolheita pode continuar a ser indicado, sem maiores restrições, às lavouras de soja que se destinariam à produção de sementes comerciais.

Este problema existe, e as próprias recomendações feitas pelos estudiosos do mundo todo, nos boletins elaborados na Reunião Conjunta WHO/FAO (26), mostram ser desejável o estudo comparativo detalhado de toxicidade e metabolismo para elucidar a razão da comparativamente alta sensibilidade do homem a este composto, além de 
estudos que relacionem a concentração no pulmão e toxicidade.

\section{LITERATURA CITADA}

1. A.O.A.C. Official methods of analysis of the Association of Official Analytical Chemists. $11^{\mathrm{a}}$. ed. Washington, A.O.A.C, 1970, 1015p.

2. Austin. R.B. \& Longden, P.C. The yield and quality of red beet seed as affected by dessiccant sprays and harvest date. Weed Research, $8: 336-345,1968$.

3. Baldwin. B.C. Translocation of diquat in plants. Nature, 198:872-873, 1963.

4. Bastidas, G.; Franco, H. \& la Cruz, R. de. Defoliantes en soya (Glycine max L. Merril). Acta Agronómica, 21(2):51-58, 1971.

5. Black, W.J.M; Calderbank, A.; Douglas, G. \& McKenna, R.H. Fotodecomposition of bipyridylium herbicides. J. Sci. Food Agric., 17:506509, 1966.

6. Brian, R.C. The bipyridylium quaternary salts. The effect of atmospheric and soil humidity on the uptake and movement of diquat and paraquat in plants. Weed Res., 6:92-303, 1966.

7. Brian, R.C. \& Ward, J. The influence of environment on potato haulm killed by diquat and its residues in the tubers. Weed Res., 7:17-130, 1967.

8. Calderbank. A. The bipyridylium herbicides. Advances in Pest Control Res., 8: 127-235. 1968.

9. Corbett, J.R. \& Miller, C.S. The persistence of 2,4 D in cotton when applied with desiccants. Weeds, 14(1):34-37, 1966.

10. Derry, J.E. \& Hamor, T.E. Fotodegradation of bipyridyliuns herbicides. Nature, 211:464-468, 1969.

11. Dunn, M.J.; Martin, R.J.; Roberts, N.L.; Slade. P.; Standen, H. \& Walker, P. Degradation of paraquat. J. Chem. Soc., 46:1468, 1966.

12. Durigan, J.F.; Durigan, J.C.; Carvalho, N.M \& Barreto, M. Aplicaçâo pré-colheita de dessecante em soja (Glycine max (L.) Merril) da cultivar "Viçoja". III - Efeitos sobre os conteúdos protéico, lipídico e de cínzas. Cientifica, 6 (3):381-385, 1978.
13. Ellis, P.; Wilkins, R.G. \& Willians, J.G. Formation of piridonas from paraquat herbicide. $\mathbf{J}$. Chem. Soc. 79:3975-3979, 1956.

14. Funderburk, H.H. \& Lawrence, J.M. Mode of action and metabolism of diquat and paraquat. Weeds, 12:259-264, 1964.

15. Garner, W.W.; Allard, H.A. \& Foubert, C.L. Oil content of seeds as effected by the nutrition of the plant. J. Agric. Res., 3(3):227-249, 1914.

16. Gigax, D.R. \& Burnside, O.C. Chemical desiccation of grain sorghum. Agron. J., 68(4):645. $649,1976$.

17. Hilton. J.L. Herbicide handbook of the weed Science Society of America. $3^{\mathrm{a}}$. ed. Champaign. Weed Sci. Society of America Champaign, 1974. p.292-296.

18. Roberts, H.M. \& Griffiths, D.J. Pre-harvest desiccation of herbage seed crops and its effects on seed quality. J.Br. Grassld Soc., 28: 189-192, 1973.

19. Rubel, A.; Rinne, R.W. \& Cavin, D.T. Protein. oil, and fathy acid in developing soybean seeds Crop. Sci. 12(6):739-741, 1972.

20. Sarruge, J.R. \& Haag. H.P. Análises químicas em plantas. Piracicaba. ESALQ-USP, 1974. $56 \mathrm{p}$.

21. Slade, P. Sub-products of paraquat fotodegradation. Nature, 270:515-520, 1965.

22. Slade. P. The fate of paraquat applied to plants. Weed Res., 6:158-167, 1966.

23. Slade, P. \& Smith. A.E. Photochemical degradation of diquat. Nature, 213:919-920, 1967.

24. Tabin, S. \& Skalski, J. Influence of some defoliants on time of maturation and yield of soybeans seeds. Ann. Univ. Mariae Curie Sklodowaska, 27:1-19, 1972.

25. Thrower, S.L.; Hallam, N.D. \& Thrower, L.B. Movement of diquat $\left(1,1^{\prime}\right.$-ethylene-2.2 -dipyridylilum) dibromide im leguminous plants. Annals Appl. Biol., 55:253-260, 1965.

26. W.H.O./F.A.O. Pesticide residues in food. Report of the 1972 Joint Meeting of the FAO Working Party of Experts on Pesticide Residues and of the W.H.O. Expert Committee on Pesticide Residues. Genebra, WHO, FAO, 1973. 48p. (FAO Agricultural Studies, 90). WHO- Tech. Rep. Series, 525.

27. Wood, G.H. \& Gosneel, J.M. Some factors affecting the translocation of radioactive paraquat in Cyperus species. Proc. South Afr. Sugar Technol. Ass., p.7, 1965. 